\title{
Wellens' Syndrome in a Patient with Chronic Cannabis Use
}

\author{
Kronik Esrar Kullanımı Olan Hastada Wellens Sendromu
}

\section{Mustafa Öztürk, (D) Rana Akkoyun, (D) Sunay Yıldırım, (D) Selman Yeniocak}

Sağlık Bilimleri Üniversitesi, İstanbul Haseki Sağlık Uygulama ve Araştırma Merkezi

\begin{abstract}
Substance abuse is a social problem that can be seen at all ages, leading to physical and mental social problems. According to the electrocardiographic (ECG) findings, a sixty-one-year-old male patient with 25 years of chronic cannabis use was considered wellens' syndrome. LAD total occlusion was detected after the patient's emergency coronary intervention. The association of wellens' syndrome, seen without coronary total occlusion and informing occlusion, with cannabis use has not been reported in the literature before. The thought of this syndrome in patients with cannabis use should be considered in terms of causing mortality rapidly.

\section{ÖZET}

Madde bağımlılığı, fiziksel, ruhsal sosyal sorunlara yol açan tüm yașlarda görülebilen bir toplumsal problemdir. 25 yll kronik esrar kullanımı olan altmış bir yaşında erkek hastada elektrokardiyografi (EKG) bulgularına göre wellens sendromu düşünüldü. Hastanın acil koroner girişim sonrası LAD total oklüzyonu saptandl. Koroner total oklüzyon olmadan görülen ve oklüzyonu haber veren wellens sendromunun esrar kullanımı ile birlikteliği literatürde daha önce bildirilmedi. Esrar kullanımı olan hastalarda da bu sendromun düşünülmesi hızla mortaliteye yolaçması açısından düşünülmesi gerekmektedir.
\end{abstract}

Key Words:

Wellens' Syndrome,

Cannabis,

Electrocardiography.

Anahtar Kelimeler: Wellens Sendromu, Esrar,

Elektrokardiyografi.

\section{GíRiş}

Madde bağımlılı̆̆ı, fiziksel, ruhsal sosyal sorunlara yol açan tüm yaşlarda görülebilen bir toplumsal problemdir. Madde kullanımına bağlı toksik etki spektrumu çok geniştir. Özellikle kardiyak etkiler morbidite ve mortaliteye yol açmaktadır. Esrar, en çok kullanılan uyuşturucu maddedir.

Wellens Sendromu, mortaliteye yol açan bir tablo olup, anterior prekordiyal derivasyonlarda (V2-4) derin, simetrik, negatif ya da bifazik T dalgası ile karakterize spesifik EKG (Elektrokardiyografi) değiş̧iklikleri olan ve kritik proksimal LAD (sol ön inen koroner arter) darlığını gösteren klinik bir durumdur. Literatüre "LAD Koroner T-Dalga Sendromu” olarak sunulmuştur $(1,3)$.

\section{OLGU}

Altmış bir yaşında erkek hasta bir gün önceki sabah başlayan 20 dakika süren yanıcı karakterde sol göğüs ağrıs1 olup geçmiş ancak sonraki gün aynı ağrı tekrarlamas1 üzerine acil servise başvurdu. Hipertansiyon ve 25 yıl süren kronik esrar bağımlılığ hikayesi mevcuttu. Tansiyon: 140/90 mm hg, nabiz dakika sayısı: 73 ritmik ateş:36,7 Saturasyon: \%97 saptandi. Elektrokardiyografi çekildi. EKG: V1-3 bifazik T dalgaları, V4-6 derin, ters T dalgaları gözlendi (Şekil 1). Troponin 0,16 saptand. Hasta akut koroner sendrom tanısı ile primer perkütan girişim için kateter laboratuvarına alındı. Koroner anjiografik girişim sonras1 LAD proksimalde $\% 90$ darlik saptand. LAD kritik lezyona perkütan koroner girişim uygulandı ve

Tablo 1. Wellen's Sendromunun klinik ve EKG kriterleri Rhinehart ve ark. (2002) ${ }^{3}$

\begin{tabular}{|l|}
\hline Anjina hikayesi \\
\hline Normal ya da hafifçe yükselmiş kardiyak enzimler (genellikle normalin iki katından az) \\
\hline V2-3 ve bazen V1-4, V5, V6 derivasyonlarda bifazik ya da ters, simetrik, derin T dalgalar1 \\
\hline İzoelektrik hatta veya minimal yüksek ST segmenti $(<1 \mathrm{~mm})$ \\
\hline Prekordiyal R dalga progresyon kaybının olmaması \\
\hline Prekordiyal Q dalgalarının yokluğu \\
\hline Rhinehardt J, Brady WJ, Perron AD, Mattu A. Electrocardiographic manifestations of Wellens’ syndrome. Am J Emerg Med. 2002; \\
20:638-643.
\end{tabular}
20:638-643. 


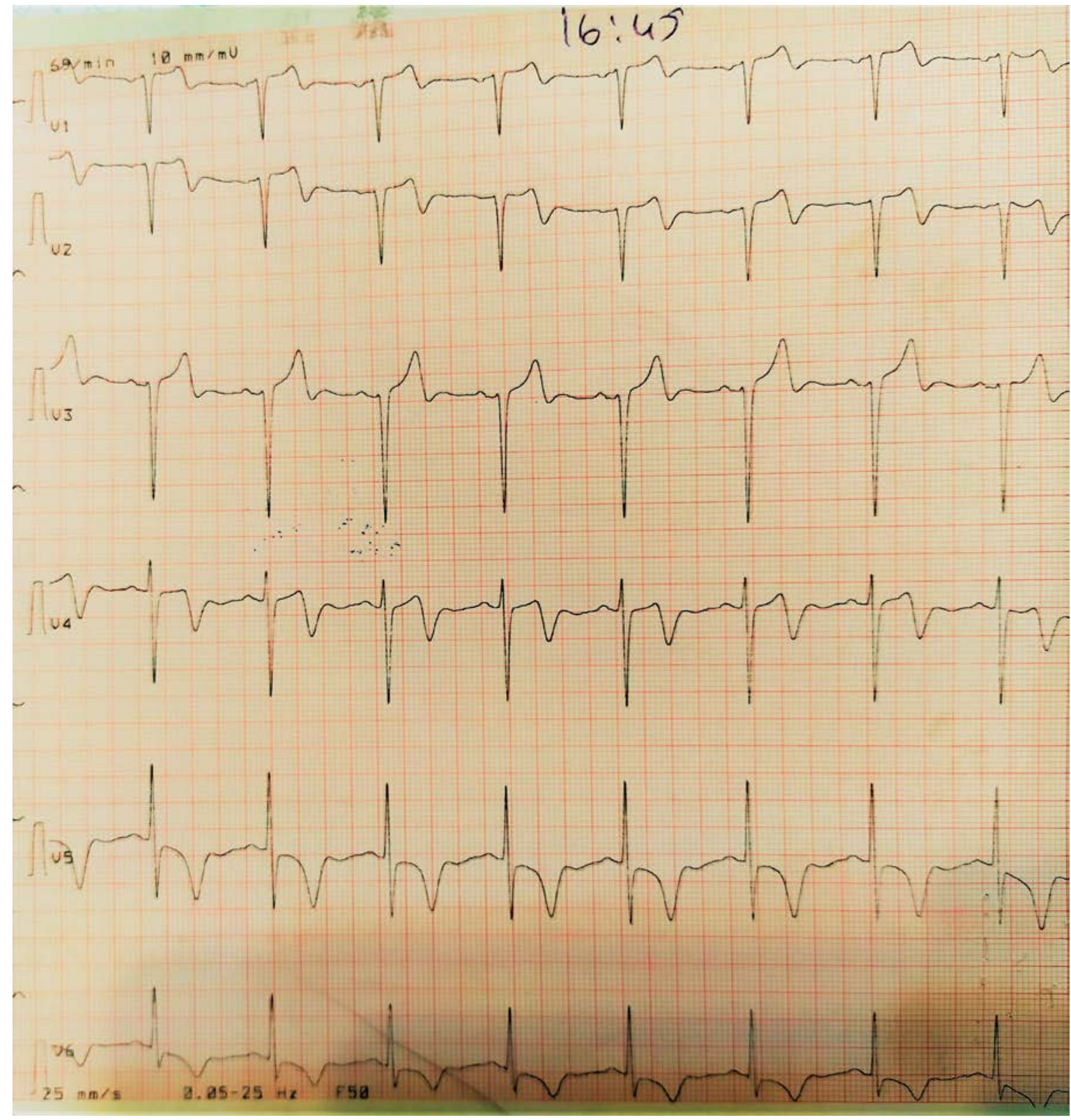

Şekil 1: Başvuru sırasında çekilen elektrokardiyografide V1-3 bifazik T dalgaları, V4-6 derin, ters T dalgaları

stent implante edildi. Kontrol transtorasik ekokardiyografide inferobazal bölüm hafif hipokinetik saptand. Medikal tedavisi düzenlenen hasta taburcu edildi.

$\mathrm{Bu}$ makalenin yayınlanması için hastadan bilgilendirilmiş onam alındı.

\section{TARTIŞMA}

Wellens Sendromu LAD total veya totale yakın oklüzyonunu gösterebilen klinik bir durumdur. Tip A veya tip B olarak sınıflandırılır. Tip A (tip 2), V2 ve V3 derivasyonlarında bifazik $\mathrm{T}$ dalgası ile karakterizedir. Tip B (tip 1) aynı derivasyonlarda derin $\mathrm{T}$ dalga inversiyonu ile karakterizedir.
Ayırıcı tanıda bifazik T dalgası görülebilen myokardiyal iskemi veya infarkt, pulmoner emboli, hipertrofik kardiyomyopati, sağ dal bloğu, kafa içi basınç artışı (KIBAS), persitan jüvenil $\mathrm{T}$ dalga paterni, brugada sendromu, hipokalemi yer almaktadır (5).

EKG tanıs1 spesifiktir. EKG bulguları V2, V3'te bazen de V1, V4, V5, V6'da bifazik veya derin, ters dönmüş T dalgaları, kardiyak biyomarkırların normal olması veya minimal,yüksekliği, ST-segment elevasyonu olmaması veya minimal olması $(<1 \mathrm{~mm})$; Prekordiyal R-dalga progresyon kaybı olmaması, Patolojik prekordiyal Q dalgası olmaması, Angina öyküsü olması olarak sıralanabilir ( Tablo 1). Vakamızda da EKG'de V1, V2, V3'te bifazik T dalgaları, V4, V5, V6'da derin, ters T dalgaları gözlendi. Troponin hafif yüksekti. 


\section{Phnx Med J. March, Volume 2 No 1}

De Zwaan ve ark. tarafından yapılan ilk çalışma, Wellens Sendromu olan hastaların \%75'inin başvurudan sonraki haftalarda geniş ön duvar miyokard enfarktüsü ile geldiğini göstermiştir. Çalışma; Wellens Sendromunun EKG bulgusunun LAD total veya totale yakın oklüzyonu gösterdiğini bildirmiştir. Bu nedenle, bu çalışma sonrası, koroner anjiyografi ve revaskülarizasyon şiddetle tavsiye edildi. Sendrom LAD akut stenozu için bir öngörü vermektedir. Vakamızda da LAD \%90 darlığı saptanmıştır.

Literatürde wellens sendromu nadir olarak bildirilmiş ayrıca literatürde Wellens Sendromu ile birlikte kronik esrar kullanımı vakası bildirilmemiștir. Madde kullanımı ile kardiak etkileri sıklıkla acil başvuru nedeni olabilmektedir (4). Vakamıda da daha önce önemsenmeyen ancak gögüste yanma şeklinde prezente olan vakada esrar kullanımı ile tetiklenen LAD total oklüzyonu saptanmıştır.
Nadir görülen ve EKG'de önceden saptanabilen yaşamı tehdit edebilen Wellens Sendromu, muhtemelen LAD total veya total okluze olmadan önce gösterilebilen ilginç bir sendromdur (6). Ancak son birkaç hafta içinde bu durumun gelişmesi ve EKG'ye yansıması, tanı zamanının ne kadar da kısıtlı olduğunu göstermektedir.

\section{SONUÇ}

Wellen’s Sendromu mortalitesi yüksek bir sendrom olup kronik madde bağımlısı olan kişilerde göğ̈̈s ağrısı olsun olmasın başvuranlarda EKG de spesifik Wellens Sendromu saptanması acil bir durumdur. Troponin ve benzeri tetkikler beklenmeden acilen primer perkutan koroner girişim gerekmektedir.

ÇIKAR ÇATIŞMASI

Tüm yazarlar çıkar çatışması olmadığını beyan eder.

\section{KAYNAKLAR}

1. De Zwaan C, Bär FW, Wellens HJ. Characteristic electrocardiographic pattern indicating a critical stenosis high in left anterior descending coronary artery in patients admitted because of impending myocardial infarction. Am Heart J. 1982; 103:730-736.

2. De Zwaan C, Bär FW, Janssen JH, Cheriex EC, Dassen WR, Brugada P, Penn OC, Wellens HJ. Angiographic and clinical characteristics of patients with unstable angina showing an ECG pattern indicating critical narrowing of the proximal LAD coronary artery. Am Heart J. 1989; 117:657-665.

3. Rhinehardt J, Brady WJ, Perron AD, Mattu A. Electrocardiographic manifestations of Wellens’ syndrome. Am J Emerg Med. 2002; 20:638643.

4. Nüfusta Tütün, Alkol ve Madde Kullanımına Yönelik Tutum ve Davranış Araştırması (TUBİM GPS Araştırması) 2018.

5. Aufderheide TP, Gibler WB. Acute ischemic coronary syndromes. In: Rosen P, Barkin R, editors. Emergency Medicine: Concepts and Clinical Practice, 4th St Louis: Mosby-Year Book; 1998.P.1688-91

6. Al-assaf O, Anas Musa MA, AlJallaf.M. Wellens’ Syndrome: The Life-Threatening Diagnosis. Circulation. 2019;140:1851-1852 